\title{
Recent progress in multidisciplinary treatment for patients with esophageal cancer
}

\author{
Masayuki Watanabe $^{1} \cdot$ Reiko Otake $^{1} \cdot$ Ryotaro Kozuki $^{1} \cdot$ Tasuku Toihata $^{1} \cdot$ Keita Takahashi $^{1} \cdot$ Akihiko Okamura $^{1}$. \\ Yu Imamura' ${ }^{1}$
}

Received: 28 August 2019 / Accepted: 4 September 2019 / Published online: 18 September 2019

(c) The Author(s) 2019, corrected publication 2020

\begin{abstract}
Esophageal cancer is one of the most aggressive gastrointestinal cancers. This review focuses on eight topics within the multidisciplinary approach for esophageal cancer. As esophagectomy is highly invasive and likely to impair quality of life, the development of less invasive strategies is expected. Endoscopic resection (ER) of early esophageal cancer is a less invasive treatment for early esophageal cancer. A recent phase II trial revealed that combined ER and chemoradiotherapy (CRT) is efficacious as an esophagus-preserving treatment for cT1bN0 squamous cell carcinoma (SCC). Esophagectomy and definitive CRT are equally effective for patients with clinical stage I SCC in terms of long-term outcome. For locally advanced resectable cancers, multidisciplinary treatment strategies have been established through several clinical trials of neoadjuvant or perioperative treatment. Minimally invasive esophagectomy may improve the outcomes of patients and CRT is a curative-intent alternative to esophagectomy. CRT with $50.4 \mathrm{~Gy}$ radiotherapy combined with salvage surgery is a promising option to preserve the esophagus. Induction chemotherapy followed by esophagectomy may improve the outcomes of patients with locally advanced unresectable tumors. Immune checkpoint inhibitors are effective for esophageal cancer, and their introduction to clinical practice is awaited.
\end{abstract}

Keywords Esophageal cancer $\cdot$ Multidisciplinary treatment $\cdot$ Esophagectomy $\cdot$ Chemoradiotherapy

\section{Introduction}

Esophageal cancer is one of the most aggressive of all gastrointestinal malignancies. The overall 5-year survival rate ranges from 15 to $25 \%$ worldwide and it is the sixth leading cause of cancer-related deaths of men [1]. In Japan, the 5 -year survival rate of patients with esophageal cancer diagnosed between 2006 and 2008 was 37.2\% (36.0\% of men and $43.9 \%$ of women) [2]. The two major histologic subtypes of esophageal cancer are squamous cell carcinoma (SCC) and adenocarcinoma (AC). It is well-known that the incidence of both subtypes varies among geographic areas: SCC has a higher prevalence in East Asia, Eastern and Southern Africa, and Southern Europe, whereas AC is much more common in North America and other parts of Europe [3]. In Japan, SCC

\footnotetext{
Masayuki Watanabe

masayuki.watanabe@jfcr.or.jp

1 Department of Gastroenterological Surgery, The Cancer Institute Hospital of Japanese Foundation for Cancer Research, 3-8-31 Ariake, Koto-ku, Tokyo 135-8550, Japan
}

is the main histologic subtype, accounting for approximately $90 \%$ of cases, but the incidence of AC is increasing [4].

Although esophagectomy remains the mainstay of treatment for esophageal cancer, it is very invasive and associated with a high incidence of morbidity and mortality [5]. Moreover, postoperative symptoms such as appetite loss, early satiety, dysphagia, aspiration, and reflux can impair the patients' quality of life [6]. Therefore, a less-invasive alternative to esophagectomy is being sought, especially for patients with early-stage disease. Unfortunately, esophageal cancer is frequently found at an advanced stage when surgery alone cannot achieve cure. For such cases, a multidisciplinary treatment strategy is required to achieve cure. This review summarizes recent progress in the multidisciplinary treatment of esophageal cancer. 


\section{Methods}

In this narrative review, we focus on eight topics: endoscopic resection for early esophageal cancer, treatment selection for cStage I (T1bN0) SCC, neoadjuvant treatment for locally advanced resectable SCC, multidisciplinary treatment strategy for locally advanced resectable $\mathrm{AC}$, recent progress in surgical technique, definitive chemoradiotherapy (CRT) and salvage esophagectomy, conversion surgery for initially unresectable SCC, and immune checkpoint blockade for esophageal cancer.

\section{Endoscopic resection for early esophageal cancer}

Endoscopic resection (ER) is a less invasive treatment for early esophageal cancer than other treatment modalities such as esophagectomy and definitive CRT. The indication for ER is decided based on the risk of lymph node metastasis. Lymph node metastasis seldom arises from carcinoma in situ or tumors confined within the lamina propria mucosae; therefore, ER can be curative for these tumors. The reported incidence of lymph node metastasis in patients with SCCs invading the muscularis mucosa and those with minimal invasion to the submucosal layer $(<200 \mu \mathrm{m}$ below the muscularis mucosa) was $9.3 \%$ and $19.6 \%$, respectively [7]. These lesions are considered to be a relative indication for ER.

The indication for ER in AC patients is still based on the same criteria as used for SCC, although there is little information on the risk of lymph node metastasis from early-stage AC. A recent Japanese multicenter retrospective study found that lymphatic invasion, the existence of a poorly differentiated component, and a lesion size $>30 \mathrm{~mm}$, were the factors associated with lymph node metastasis in patients with mucosal or submucosal ACs [8]. In that study, tumors limited to within $500 \mu \mathrm{M}$ of submucosal invasion had a low incidence of lymph node metastasis unless they had the risk factors mentioned above. Based on these results, the clinical features of early-stage esophageal AC seem to be more similar to those of early gastric cancer [9] than to those of esophageal SCC.

Recently, Muto et al. reported the results of the Japan Clinical Oncology Group (JCOG) 0508 trial, which was a multi-institutional, single-arm phase II study to evaluate the efficacy and safety of combined ER and CRT in patients with cT1bN0M0 SCC [10]. The study enrolled patients with cT1bN0M0 SCCs with tumor size $\leq 5 \mathrm{~cm}$ and $\leq 3 / 4$ circumference. They divided the patients into three groups based on the pathologic results: Group A included 74 patients with pT1a with negative resection margin and no vascular invasion; Group B included 87 patients with pT1b with negative resection margin or pT1a with vascular invasion; and Group $\mathrm{C}$ included 15 patients with pT1b with positive resection margin. The Group A patients were followed up without any additional treatment; the Group B patients underwent prophylactic CRT consisting of $41.4 \mathrm{~Gy} / 23$ fractions (fr) irradiation to the field, including locoregional lymph nodes, combined with 5-fluorouracil + cisplatin (CF); and the Group C patients underwent definitive CRT consisting of $50.4 \mathrm{~Gy} / 28 \mathrm{fr}$ with a 9-Gy boost to the primary site. The 3 -year overall survival rate of the Group B patients, the primary endpoint, was $90.7 \%$ [90\% confidence interval (CI) 84.0-94.7], suggesting that the combined ER and CRT strategy is efficacious as esophagus-preserving treatment for cT1bNOM0 SCC.

\section{Treatment selection for cStage I (cT1 bN0) SCC}

Esophagectomy is the standard treatment for cStage I SCC, worldwide. The current National Comprehensive Cancer Network Guideline (Version 2.2019) in the USA states that esophagectomy is the standard treatment for cT1bN0 SCC and that definitive CRT may be an appropriate option for patients who decline surgery [11]. According to the European Society for Medical Oncology Clinical Practice Guidelines, surgery is the treatment of choice for limited disease (cT1-T2N0M0), irrespective of the histologic subtype, although definitive CRT is recommended for patients not willing to undergo esophageal surgery or who are medically unfit for major surgery [12]. The current Japanese guideline states that the selection between surgery and CRT should be made after assessing the patient's surgical tolerability [13].

In Japan, efforts are being made to establish an esophagus-sparing treatment for T1bN0 SCC using definitive CRT, even for patients who are fit for surgery. The JCOG9708 trial, a phase II study of definitive CRT for clinical stage I SCC, revealed 2- and 5-year overall survival rates of 93\% and $76 \%$, respectively, which are comparable to those of esophagectomy [14]. The results of the JCOG0502 trial, which is a parallel-group trial of esophagectomy versus CRT for patients with clinical Stage I esophageal carcinoma, have been reported recently [15]. Although this study had a randomized part, it was terminated because of poor patient accrual. In the comparison of the non-randomized part, the 3- and 5-year overall survival rates of CRT group were 93.1\% (95\% CI 87.9-96.1) and 85.5\% (95\% CI 78.9-90.1), respectively, while those of the surgery group were $94.7 \%$ (95\% CI 90.8-97.0) and 86.5\% (95\% CI 81.0-90.5), respectively. The adjusted hazard ratio (HR) was 1.082 (95\% CI 0.674-1.640), suggesting the non-inferiority of CRT against esophagectomy. 


\section{Neoadjuvant treatment for locally advanced resectable SCC}

The long-term outcomes of surgery alone for patients with locally advanced SCC are unsatisfactory. Many trials on adjuvant or neoadjuvant therapy have been conducted to investigate efficacy. Table 1 shows the clinical trials that are the basis of current standard treatment for locally advanced, resectable esophageal SCC. The JCOG9204 trial, which compared surgery alone versus surgery followed by postoperative chemotherapy using the $\mathrm{CF}$ regimen, revealed that postoperative chemotherapy extended the disease-free survival of patients with node-positive clinical stage II/III SCC [16]. The JCOG9907 trial compared preoperative CF followed by esophagectomy versus esophagectomy followed by postoperative $\mathrm{CF}$ for patients with clinical stage II/III SCC [17]. The trial clarified that the overall survival of the preoperative chemotherapy group was significantly better than that of the postoperative chemotherapy group. Based on these results, neoadjuvant chemotherapy with $\mathrm{CF}$ is the current standard treatment for cStage II/III SCC in Japan. For patients who undergo upfront surgery, postoperative $\mathrm{CF}$ is recommended if the pathologic examination detects lymph node metastasis [13]. Currently, a three-arm phase III trial comparing CF versus docetaxel versus cisplatin plus 5-fluorouracil (DCF) versus CRT using $\mathrm{CF}$ as preoperative therapy for locally advanced esophageal cancer (JCOG1109) is ongoing [18].

In Western countries, preoperative CRT is the gold standard for patients with locally advanced resectable SCC, based on the results of the CROSS trial, which compared surgery alone with neoadjuvant CRT consisting of 40 Gy irradiation combined with carboplatin plus paclitaxel followed by surgery $[19,20]$. Although the CROSS regimen provided survival benefits to patients with both histologic subtypes, the survival benefit was more evident in those with SCC than in those with AC.
In the neoadjuvant CRT arm of the CROSS trial, a complete response was seen pathologically in the resected specimen from $49 \%$ of patients with SCC and $23 \%$ of patients with $\mathrm{AC}$ [19]. Based on these high complete response rates, the necessity of standard esophagectomy after neoadjuvant CRT has been questioned, especially for patients who responded sufficiently to neoadjuvant CRT. The preSANO trial was a prospective, multicenter, diagnostic cohort study to establish the accuracy of detection of residual disease after neoadjuvant CRT with different diagnostic approaches [21]. This study revealed that clinical evaluation with endoscopic ultrasonography, bite-on-bite biopsies, and fine-needle aspiration of suspicious lymph nodes was adequate for the detection of locoregional residual disease, with PET-CT for the detection of interval metastases. Based on the result, surveillance using this combination is being assessed in a phase III trial (SANO trial) [22].

\section{Multidisciplinary treatment strategy for locally advanced resectable AC}

The standard treatment for locally advanced AC in Japan has not yet been established because of the limited number of cases of AC. In Western countries, several important clinical trials have demonstrated the efficacy of neoadjuvant or perioperative therapy versus surgery alone (Table 2). The OEO2 trial, in which $66 \%$ of the patients had AC, revealed that neoadjuvant $\mathrm{CF}$ extended overall survival more effectively than surgery alone [23]. The Medical Research Council Adjuvant Gastric Infusional Chemotherapy (MAGIC) trial, in which $11 \%$ of patients had junctional esophageal cancer and $14 \%$ had lower esophageal AC, compared three cycles of epirubicin, cisplatin, and 5-fluorouracil (ECF) before and after surgery with surgery alone [24]. The 5-year overall survival rates of the perioperative chemotherapy group versus the surgery alone group were $36 \%$ versus $23 \%$, respectively
Table 1 Clinical trials that are the basis of current standard treatment for locally advanced resectable esophageal squamous cell carcinoma

\begin{tabular}{|c|c|c|c|c|}
\hline Study name (year) & Histologic subtype $^{\mathrm{a}}$ & Treatment arms ${ }^{\mathrm{b}}$ & Main results ${ }^{\mathrm{c}}$ & $P$ value \\
\hline JCOG9204 (2003) & SCC & $\begin{array}{l}\text { Surgery alone } \\
\text { Surgery }+\mathrm{CF}\end{array}$ & $\begin{array}{l}5 \text {-year DFS 45\% } \\
5 \text {-year DFS 55\% }\end{array}$ & 0.037 \\
\hline JCOG9907 (2012) & SCC & $\begin{array}{l}\text { Surgery }+\mathrm{CF} \\
\mathrm{CF}+\text { surgery }\end{array}$ & $\begin{array}{l}5 \text {-year OS } 43 \% \\
5 \text {-year OS 55\% }\end{array}$ & 0.04 \\
\hline CROSS (2012) & $\mathrm{SCC} / \mathrm{AC}$ & $\begin{array}{l}\text { Surgery alone } \\
\text { CRT + surgery }\end{array}$ & $\begin{array}{l}\text { Median OS } 24.0 \mathrm{M} \\
\text { Median OS } 49.4 \mathrm{M}\end{array}$ & 0.003 \\
\hline JCOG1109 (ongoing) & SCC & $\begin{array}{l}\mathrm{CF}+\text { surgery } \\
\mathrm{DCF}+\text { surgery } \\
\text { CF-RT + surgery }\end{array}$ & - & - \\
\hline
\end{tabular}

${ }^{a} S C C$ squamous cell carcinoma, $A C$ adenocarcinoma

${ }^{\mathrm{b}} C F$ cisplatin +5-fluorouracil, $C R T$ chemoradiotherapy, $D C F$ docetaxel+cisplatin +5 -fluorouracil, $R T$ radiotherapy

${ }^{\mathrm{c}} D F S$ disease-free survival, $O S$ overall survival 
Table 2 Clinical trials of multidisciplinary treatment strategy for locally advanced resectable esophageal adenocarcinoma

\begin{tabular}{|c|c|c|c|c|}
\hline Study name (year) & Histologic subtype $^{a}$ & Treatment arms ${ }^{\mathrm{b}}$ & Main results ${ }^{c}$ & $P$ value \\
\hline OEO2 (2002) & $\mathrm{SCC}, \mathrm{AC}$ & $\begin{array}{l}\text { Surgery alone } \\
\mathrm{CF}+\text { surgery }\end{array}$ & $\begin{array}{l}5 \text {-year OS 17\% } \\
5 \text {-year OS 23\% }\end{array}$ & 0.03 \\
\hline MAGIC (2006) & Esophagogastric AC & $\begin{array}{l}\text { Surgery alone } \\
\mathrm{ECF}+\text { surgery }+\mathrm{ECF}\end{array}$ & $\begin{array}{l}5 \text {-year OS } 23 \% \\
5 \text {-year OS } 36 \%\end{array}$ & 0.009 \\
\hline $\begin{array}{l}\text { FNCLCC-FFCD } \\
9703(2011)\end{array}$ & Esophagogastric AC & $\begin{array}{l}\text { Surgery alone } \\
\mathrm{CF}+\text { surgery }(+\mathrm{CF})\end{array}$ & $\begin{array}{l}5 \text {-year OS } 24 \% \\
5 \text {-year OS } 38 \%\end{array}$ & 0.02 \\
\hline CROSS (2012) & $\mathrm{SCC}, \mathrm{AC}$ & $\begin{array}{l}\text { Surgery alone } \\
\text { CRT + surgery }\end{array}$ & $\begin{array}{l}\text { Median OS } 24.0 \mathrm{M} \\
\text { Median OS } 49.4 \mathrm{M}\end{array}$ & 0.003 \\
\hline FLOT4 (2017) & Esophagogastric AC & $\begin{array}{l}\text { ECF or ECX + surgery }+ \text { ECF or ECX } \\
\text { FLOT }+ \text { surgery }+ \text { FLOT }\end{array}$ & $\begin{array}{l}\text { Median OS } 35 \mathrm{M} \\
\text { Median OS } 50 \mathrm{M}\end{array}$ & 0.012 \\
\hline Neo-AEGIS (ongoing) & Esophagogastric AC & $\begin{array}{l}\text { CRT + surgery (CROSS) } \\
\text { Peri CT (ECF, ECX, EOF, EOX) }\end{array}$ & - & - \\
\hline ESOPEC (ongoing) & Esophagogastric AC & $\begin{array}{l}\text { CRT + surgery (CROSS) } \\
\text { FLOT + surgery + FLOT }\end{array}$ & - & - \\
\hline TOPGEAR (ongoing) & Esophagogastric AC & $\begin{array}{l}\text { Peri CT }(\mathrm{ECF} / \mathrm{ECX}) \\
\text { Peri CRT }(\mathrm{ECF}+\mathrm{CRT}+\text { surgery + ECF/ECX) }\end{array}$ & - & - \\
\hline
\end{tabular}

${ }^{\text {a } S C C}$ squamous cell carcinoma, $A C$ adenocarcinoma

${ }^{\mathrm{b}} C F$ cisplatin + 5-fluorouracil, $E C F$ epirubicin + cisplatin + 5-fluorouracil, $C R T$ chemoradiotherapy, ECX epirubicin + cisplatin + xeloda, FLOT 5-fluorouracil + leucovorin + oxaliplatin + taxotere, $D C F$ docetaxel + cisplatin + 5-fluorouracil, Peri CT perioperative chemotherapy

${ }^{\mathrm{c}} D F S$ disease-free survival, $O S$ overall survival

$(P=0.009)$. Notably, the efficacy of perioperative chemotherapy was independent of the tumor location. The FNCLCC-FFCD trial compared perioperative CF with surgery alone and found that the overall survival of the perioperative chemotherapy group was significantly better than that of the surgery alone group [25]. The CROSS trial also demonstrated the efficacy of neoadjuvant CRT in patients with AC $[19,20]$. The FLOT4 trial was a randomized, phase II/III trial that evaluated the safety and efficacy of the docetaxel-based triplet FLOT (fluorouracil plus leucovorin, oxaliplatin and docetaxel) as perioperative chemotherapy for locally advanced, resectable AC [26]. Phase III of this study revealed that overall survival was significantly better in the FLOT group than in the ECF/ECX group (HR, 0.77; 95\% CI 0.63-0.94).

Several phase III trials comparing perioperative chemotherapy versus neoadjuvant chemoradiotherapy for AC are ongoing. The Neo-AEGIS trial is a phase III trial comparing the modified MAGIC regimen (ECF/ECX or EOF/ EOX) versus neoadjuvant CRT with the CROSS regimen [27]. The ESOPEC trial is a randomized controlled trial comparing perioperative chemotherapy with the FLOT regimen versus neoadjuvant CRT with the CROSS regimen [28]. The TOPGEAR trial is an international phase III trial comparing perioperative ECF alone versus ECF with CRT. These trials may change the standard treatment for locally advanced resectable esophageal $\mathrm{AC}$ in the near future [29].

\section{Recent progress in surgical techniques}

Minimally invasive esophagectomy (MIE) using thoracoscopy and/or laparoscopy is being performed increasingly, worldwide. According to the Annual Report from The Japanese Association for Thoracic Surgery, MIE was adopted for 1036 patients (51.3\%) with superficial cancer and 1734 patients (42.0\%) with advanced cancer in Japan during 2015 [30]. Two randomized controlled trials have been conducted to evaluate the efficacy of MIE compared with traditional open esophagectomy (OE). The TIME trial compared MIE versus $\mathrm{OE}$ for $\mathrm{cT} 1-3, \mathrm{~N} 0-1, \mathrm{M} 0$ esophageal cancer [31]. The primary outcome was pulmonary infection within the first 2 weeks and during the whole stay in hospital. There were 56 patients assigned to the OE group and 59 patients assigned to the MIE group. Pulmonary infection developed in the first 2 weeks in $16(29 \%)$ and $5(9 \%)$ of the OE and MIE group patients, respectively [relative risk (RR), 0.30; 95\% CI 0.12-0.76; $P=0.005$ ], while 19 (34\%) and $7(12 \%)$, respectively, suffered pulmonary infection in hospital (RR, $0.35 ; 95 \%$ CI $0.16-0.78 ; P=0.005)$. The hospital stay was significantly shorter for the MIE group than for the OE group. The short-term QOL was better in MIE group than in OE group. Three-year follow-up of this trial revealed no difference in disease-free or overall 3-year survival for $\mathrm{OE}$ and MIE [32]. The MIRO trial compared the transthoracic open procedure (open procedure) versus a hybrid minimally invasive procedure using a laparoscopic approach (hybrid 
procedure) in patients undergoing Ivor-Lewis esophagectomy [33]. The primary endpoint was intraoperative or postoperative complications of Clavien-Dindo Grade II or higher within 30 days. There were 105 patients assigned to undergo the hybrid procedure and 104 assigned to undergo the open procedure group. A total of 37 patients (36\%) in the hybrid procedure group and 67 (64\%) in the open procedure group suffered a major intraoperative or postoperative complication (odds ratio, $0.31 ; 95 \%$ CI $0.18-0.55 ; P<0.001$ ). The 3-year survival rate was $67 \%$ (95\% CI 57-75) for the hybrid procedure group and 55\% (95\% CI 45-64) for the open procedure group. Although the difference was not significant, the 3-year overall survival tended to be better in the hybrid procedure group than in the open procedure group.

In Japan, patient registration for the National Clinical Database (NCD) commenced in January, 2011. The NCD project contains the records of $\geq 95 \%$ of the operations performed by general surgeons in Japan [34]. Several studies evaluated the short-term outcomes of MIE and OE, using the NCD data. The first study analyzed postoperative complication and mortality after OE and MIE for 5,354 patients who underwent esophagectomy in 2011 [5]. Overall morbidity was significantly higher in the MIE group than in the OE group (44.3\% vs. $40.8 \%, P=0.016)$. In particular, the incidences of anastomotic leakage and reoperation within 30 days were significantly higher in the MIE group than in the OE group $(14.9 \%$ and $8.0 \%, P=0.016$; vs. $12.5 \%$ and $5.6 \%, P=0.001$ ). A subsequent study evaluated 9,584 patients with thoracic esophageal cancer who underwent esophagectomy in 2011-2012 [35]. In that study, one-byone matching between the OE and MIE groups based on estimated propensity scores for each patient was carried out. After propensity score matching, the operative time was significantly longer in the MIE group than in the OE group (526 \pm 149 vs. $461 \pm 156$ min, $P<0.001$ ), while blood loss was remarkably less in the MIE group than in the OE group $(442 \pm 6121$ vs. $608 \pm 591 \mathrm{ml}, P<0.001)$. Both the incidence of atelectasis and the population of patients who required more than $48 \mathrm{~h}$ of postoperative mechanical ventilation were significantly lower in the MIE group than in the OE group, whereas the incidence of pneumonia was similar in the two groups. The reoperation rate within 30 days was significantly higher in the MIE group than in the OE group (7.0 vs. 5.3\%, $P=0.004)$. The latest analysis included 24,233 esophagectomies for esophageal cancer performed between 2012 and 2016 [36]. That study analyzed the influence of preoperative treatment and surgical procedures on short-term outcomes. The total surgery-related mortality rate was significantly lower in the MIE group than in the OE group (1.7\% vs. $2.4 \%$, $P<0.001)$. MIE was superior or equivalent to $\mathrm{OE}$ in terms of the incidence of postoperative morbidities and surgeryrelated mortality, regardless of the type of preoperative treatment. MIE performed with no preoperative treatment was associated with a lower incidence of pulmonary morbidities, prolonged ventilation for more than $48 \mathrm{~h}$, unplanned intubation, surgical site infection, and sepsis. However, reoperation within 30 days was more frequent in the MIE group than in the OE group among patients who underwent esophagectomy without preoperative treatment. Currently, a phase III trial comparing MIE versus OE is ongoing in Japan [37].

Mediastinoscopy-assisted transhiatal esophagectomy (MATHE) represents another MIE option, which has the potential benefit of decreasing pulmonary complications by avoiding one-lung ventilation [38]. MATHE was considered as a less invasive option and the insufficient mediastinal lymphadenectomy was overcome by inserting a mediastinoscope from the cervical wound using a single-incision laparoscopic surgery device to enable upper mediastinal lymph node dissection under a sufficient mediastinoscopic view with carbon dioxide insufflation [39]. Fujiwara et al. reported that the median number of mediastinal lymph nodes resected by the novel MATHE was 21, achieving an R0 resection rate of 95\% [40]. Postoperative pneumonia developed in 4 of 60 patients (6.7\%). Mori et al. reported a robotic-assisted technique of MATHE [41]. In their retrospective comparison, the number of harvested mediastinal lymph nodes was comparable in the robotic-assisted MATHE and conventional transthoracic esophagectomy [42].

Robotic surgical systems were developed to overcome the technical limitations of conventional minimally invasive surgery. Robotic-assisted MIE (RAMIE) was introduced in 2003 [43], since when several case series have reported its safety with good oncological outcomes [44, 45]. The ROBOT trial was a single-center randomized controlled trial comparing RAMIE with open thoracic esophagectomy (OTE) [46]. The primary endpoint was the percentage of overall surgery-related postoperative complications of Clavien-Dindo Grade II or higher. In that study, 112 patients were randomized to undergo either RAMIE or OTE. The overall complication rate was significantly lower in the RAMIE group than in the OTE group (59\% vs. $80 \%$, $P=0.02$ ). Notably, both pulmonary complications ( $32 \%$ vs. $58 \%, P=0.005)$ and cardiac complications (22\% vs. $47 \%$, $P=0.006$ ) were significantly lower in the RAMIE group than in the OTE group. Although this study provided evidence for the use of RAMIE to improve the short-term outcomes of esophagectomy, the benefits of RAMIE over conventional MIE are not entirely clear and its cost-effectiveness is frequently challenged. Further research is required to clarify the advantages of RAMIE over MIE.

\section{Definitive chemoradiotherapy and salvage esophagectomy}

Definitive CRT with curative intent is an alternative to esophagectomy for patients who decline or are unfit 
for surgery. For patients with clinical Stage I SCC, the JCOG0502 trial demonstrated the survival non-inferiority of definitive CRT against esophagectomy, already mentioned [15]. However, it should be noted that 21 of the 159 patients (13.2\%) in the CRT group underwent salvage surgery. The JCOG9906 trial was a phase II trial that explored the efficacy and safety of CRT for patients with cStage II/III esophageal SCC [47], while the JCOG9907 compared preoperative chemotherapy followed by surgery versus surgery followed by postoperative chemotherapy for similar patients [17]. Both trials had almost identical eligibility criteria. The JCOG1406-A was an exploratory analysis using pooled data from two prospective trials: JCOG9906 and JCOG9907 [48]. Overall survival was significantly better in the preoperative chemotherapy group, followed by the esophagectomy group, than in the CRT group (adjusted HR 1.72; 95\% CI 1.19-2.50). Unlike for patients with cStage I SCC, for patients with cStage II/III SCC, CRT is not standard treatment, but an alternative to multidisciplinary treatment with esophagectomy as the main modality.

Although salvage esophagectomy can provide a chance of cure when definitive CRT fails, it is associated with high morbidity and mortality rates. We reported previously that a high radiation dose $\geq 60$ Gy was a significant predisposing factor to postoperative pulmonary complications [49]. The INT0123 RTOG 94-05 trial compared the locoregional control, survival, and toxicity associated with CRT using highdose (64.8 Gy) versus standard-dose (50.4 Gy) radiation therapy for patients with esophageal cancer [50]. The higher radiation dose did not increase survival or locoregional control, and the standard radiation dose for definitive CRT is considered to be $50.4 \mathrm{~Gy}$. Based on this result, a phase II study of concurrent CRT at the dose of $50.4 \mathrm{~Gy}$ with elective nodal irradiation (modified RTOG regimen) for stage II-III esophageal carcinoma was conducted [51]. A complete response was achieved in 36 of 51 patients (70.6\%), and the 1 - and 3-year overall survival rates were $88.2 \%$ and $63.8 \%$, respectively. There was no mortality of the 8 patients who underwent salvage esophagectomy. The JCOG0909 trial was the single-arm phase II study to verify the efficacy and safety of CRT with the modified RTOG regimen followed by salvage treatment for locoregional failure in patients with cStage II/III esophageal SCC [52]. The complete response rate was $59 \%$, the 3 -year overall survival rate was $74.2 \%$, and the 3-year esophagectomy-free survival was $63.6 \%$. Major complications of Clavien-Dindo Grade III or more developed in 5 (20.2\%) of 25 patients who underwent salvage esophagectomy and $1(4.0 \%)$ died. These results show that CRT with the modified RTOG regimen is a promising option to preserve the esophagus.

Definitive CRT is the standard treatment for locally advanced, unresectable esophageal cancer. Ohtsu et al. reported the efficacy of definitive CRT consisting of concurrent 60 Gy radiotherapy with $\mathrm{CF}$ for patients with T4 and/or M1 lymph node (LYM) esophageal cancer [53]. Complete response was achieved in 18 (33\%) of 54 patients, 9 of whom had T4 disease. The JCOG9516 trial was a phase II study of CRT for T4 and/or M1 LYM [54]. The objective response rate was $68.3 \%$, the complete response rate was $15 \%$, the median survival time was 10 months, and the 2 -year survival rate was $31.5 \%$. The JCOG0303 trial was a randomized phase II/III study comparing standard CF (arm A) versus daily low-dose $\mathrm{CF}$ ( $\mathrm{arm} \mathrm{B}$ ) with concurrent $60 \mathrm{~Gy}$ radiotherapy for SCC patients with $\mathrm{T} 4$ and/or unresectable regional lymph node metastasis [55]. There was no difference in the toxicities between the groups. The median and the 3 -year overall survivals were 13.1 months and $25.9 \%$, respectively, for arm A, and 14.4 months and $25.7 \%$ for arm B. Although the low-dose CF regimen was expected to be more effective and less toxic than the standard CF, there was no obvious advantage of the low-dose $\mathrm{CF}$ regimen over the standard CF regimen. The KDOG0501 trial was a phase I/ II trial to evaluate the safety and efficacy of definitive CRT with the DCF regimen (DCF-R) for locally advanced SCC [56, 57]. Phase I suggested that DCF-R was tolerable and active in patients with advanced esophageal cancer [56]. Phase II investigated the efficacy of RCF-R for patients with T4 and/or M1LYM. The total radiation dose was initially $61.2 \mathrm{~Gy}$, but this was lowered to multiple-field irradiation with 50.4 Gy to decrease esophagitis and late toxicity [57]. The clinical complete response rate was $52.4 \%$ overall: $33.3 \%$ in the 61.2 Gy group and $60.0 \%$ in the 50.4 Gy group. The median overall survival was 29.0 months and the 3 -year survival rate was $43.9 \%$. Although major toxicity of Grade 3 or more was frequently observed, DCF-R is suggested to be a promising regimen for patients with locally advanced, unresectable SCC.

\section{Conversion surgery for initially unresectable SCC}

The availability of effective chemotherapy regimens and the development of innovational surgical techniques have resulted in more cases that would once have been considered unresectable, now being resectable following treatment [58]. This strategy is known as conversion therapy and the surgery performed is called conversion surgery. Although conversion therapy is commonly performed for patients with colorectal cancer, the clinical significance of such a strategy for patients with esophageal cancer remains unclear. A multicenter phase II trial assessing the safety and efficacy of chemoselection with induction chemotherapy using DCF and subsequent conversion surgery for initially unresectable locally advanced esophageal SCC was conducted in Japan [59]. Treatment started with induction DCF, followed by conversion surgery if resectable, or by CRT if unresectable. Twenty of the 48 
patients enrolled (41.7\%) underwent conversion surgery and R0 resection was achieved in 19 (39.6\%). In addition to the patients who underwent conversion surgery, clinical complete response after CRT was confirmed in 4 patients (8.3\%) and the 1-year overall survival rate of the enrolled patients was $67.9 \%$. These results suggest that chemoselection with DCF induction chemotherapy followed by conversion surgery is a promising strategy for patients with locally advanced, unresectable SCC. Currently, a phase III trial comparing this strategy versus definitive chemoradiotherapy plus salvage surgery (JCOG1510 trial) is ongoing [60].

\section{Immune checkpoint blockade for esophageal cancer}

The development of the immune checkpoint blockade has launched a new era of immunotherapy. Programmed death-1 (PD-1), together with its ligand (PD-L1) inhibit the response of $\mathrm{T}$ cells to tumor cells [61]. An open-label, single-arm, multi-center phase II trial was conducted to assess the safety and activity of nivolumab, an antiPD-1 antibody, monotherapy for metastatic esophageal SCC in patients refractory to standard chemotherapy [51]. Eleven of the 64 patients enrolled (17\%) had an objective response (partial response rate of $15.6 \%$ and complete response rate of $1.6 \%$ ) and the median overall survival was 10.8 months (95\% CI 7.4-13.3). A phase III trial comparing nivolumab alone and docetaxel or paclitaxel (NCT02569242) is ongoing. The results from the esophageal cancer cohort of KEYNOTE-028, a multicohort phase IB trial of pembrolizumab, another anti-PD1 antibody, in patients with PD-L1 positive advanced solid tumors have also been reported [62]. The study included patients with either SCC or AC, for whom standard chemotherapy failed. Among the 23 patients enrolled, 18 (78\%) had SCC. The objective response rate was $28 \%$ (5/18) for patients with SCC and 40\% (2/5) for those with AC. The median duration of response was 15 months and the median overall survival was 7.0 months. The KEYNOTE-181 trial was a phase III study comparing pembrolizumab versus the investigator's choice chemotherapy as second-line therapy for patients with advanced/ metastatic SCC or AC of the esophagus or Siewert type I AC of the esophagogastric junction [63]. Among the 628 patients enrolled, 401 had SCC and 222 had a combined positive score $(\mathrm{CPS}) \geq 10$. Pembrolizumab was superior to chemotherapy for overall survival when the CPS $\geq 10$ (median 9.3 vs. 6.9 months; HR 0.69 ; 95\% CI $0.52-0.93 ; P=0.0074)$. A phase III trial comparing chemotherapy plus pembrolizumab versus chemotherapy alone as first-line therapy for advanced esophageal cancer (NCT03189719) is ongoing [64].

\section{Conclusion}

Esophageal cancer is challenging to treat and requires a multidisciplinary approach to improve the outcomes. The results of further and ongoing clinical trials will contribute to establishing the most appropriate interdisciplinary strategy for each stage of each histologic subtype.

Funding None.

\section{Compliance with ethical standards}

Conflict of interest The authors declare that they have no conflict of interest.

Open Access This article is licensed under a Creative Commons Attribution 4.0 International License, which permits use, sharing, adaptation, distribution and reproduction in any medium or format, as long as you give appropriate credit to the original author(s) and the source, provide a link to the Creative Commons licence, and indicate if changes were made.

The images or other third party material in this article are included in the article's Creative Commons licence, unless indicated otherwise in a credit line to the material. If material is not included in the article's Creative Commons licence and your intended use is not permitted by statutory regulation or exceeds the permitted use, you will need to obtain permission directly from the copyright holder.

To view a copy of this licence, visit http://creativecommons.org/ licenses/by/4.0/.

\section{References}

1. Pennathur A, Gibson MK, Jobe BA, Luketich JD. Oesophageal carcinoma. Lancet. 2013;381:400-12.

2. Center of Cancer Control and Information Services NCC. Cancer Statistics in Japan, Cancer Information Service. 2019. https ://ganjoho.jp/en/professional/statistics/table_download.html. Accessed 10 Aug.

3. Huang F-L, Yu S-J. Esophageal cancer: risk factors, genetic association, and treatment. Asian J Surg. 2018;41:210-5.

4. Watanabe M. Recent topics and perspectives on esophageal cancer in Japan. JMA J. 2018;1:30-9.

5. Takeuchi H, Miyata H, Gotoh M, Kitagawa Y, Baba H, Kimura W, et al. A risk model for esophagectomy using data of 5354 patients included in a Japanese nationwide web-based database. Ann Surg. 2014;260:259-66.

6. Elliott JA, Docherty NG, Eckhardt HG, Doyle SL, Guinan EM, Ravi N, et al. Weight loss, satiety, and the postprandial gut hormone response after esophagectomy: a prospective study. Ann Surg. 2017;266:82-90.

7. Fujishiro M, Kodashima S. Indications, techniques, and outcomes of endoscopic submucosal dissection for esophageal squamous cell carcinoma. Esophagus. 2009;6:143-8.

8. Ishihara R, Oyama T, Abe S, Takahashi H, Ono H, Fujisaki J, et al. Risk of metastasis in adenocarcinoma of the esophagus: a multicenter retrospective study in a Japanese population. J Gastroenterol. 2017;52:800-8.

9. Japanese Gastric Cancer Association. Japanese gastric cancer treatment guidelines 2014 (ver. 4). Gastric Cancer. 2017;20:1-19. 
10. Muto M, Minashi K, Nihei K, Mizusawa J, Yano T, Ezoe Y, et al. Efficacy of combined endoscopic resection and chemoradiotherapy for clinical stage I esophageal squamous cell carcinoma (ESCC): a single-arm confirmatory study (JCOG0508). J Clin Oncol. 2016;34:4013-4013.

11. National Comprehensive Cancer Network. NCCN Clinical Practice Guidelines in Oncology. Esophageal and esophagogastric junction cancers. Version 2.2019. 2019. https://www.nccn.org/ professionals/physician_gls/pdf/esophageal_blocks.pdf. Accessed 12 Aug.

12. Lordick F, Mariette C, Haustermans K, Overmannova R, Arnold D. Oesophageal cancer: ESMO clinical practice guidelines for diagnosis, treatment and follow-up. Ann Oncol. 2016;27:v50-v5757.

13. Kitagawa Y, Uno T, Oyama T, Kato K, Kato H, Kawakubo H, et al. Esophageal cancer practice guidelines 2017 edited by the Japan Esophageal Society: part 1. Esophagus. 2019;16:1-24.

14. Kato H, Sato A, Fukuda H, Kagami Y, Udagawa H, Togo A, et al. A phase II trial of chemoradiotherapy for stage I esophageal squamous cell carcinoma: Japan Clinical Oncology Group Study (JCOG9708). Jpn J Clin Oncol. 2009;39:638-43.

15. Kato K, Igaki H, Ito Y, Nozaki I, Daiko H, Yano M, et al. Parallel-group controlled trial of esophagectomy versus chemoradiotherapy in patients with clinical stage I esophageal carcinoma (JCOG0502). J Clin Oncol. 2019;37:7-7.

16. Ando N, Iizuka T, Ide H, Ishida K, Shinoda M, Nishimaki T, et al. Surgery plus chemotherapy compared with surgery alone for localized squamous cell carcinoma of the thoracic esophagus: a Japan Clinical Oncology Group Study-JCOG9204. J Clin Oncol. 2003;21:4592-6.

17. Ando N, Kato H, Igaki H, Shinoda M, Ozawa S, Shimizu H, et al. A randomized trial comparing postoperative adjuvant chemotherapy with cisplatin and 5-fluorouracil versus preoperative chemotherapy for localized advanced squamous cell carcinoma of the thoracic esophagus (JCOG9907). Ann Surg Oncol. 2012;19:68-74.

18. Nakamura K, Kato K, Igaki H, Ito Y, Mizusawa J, Ando N, et al. Three-arm phase III trial comparing cisplatin plus 5-FU (CF) versus docetaxel, cisplatin plus 5-FU (DCF) versus radiotherapy with $\mathrm{CF}$ (CF-RT) as preoperative therapy for locally advanced esophageal cancer (JCOG1109, NExT study). Jpn J Clin Oncol. 2013;43:752-5.

19. van Hagen $P$, Hulshof $M C$, van Lanschot JJ, van Berge Henegouwen MI, Wijnhoven BPL, Richel DJ, et al. Preoperative chemoradiotherapy for esophageal or junctional cancer. $\mathrm{N}$ Engl J Med. 2012;366:2074-84.

20. Shapiro J, van Lanschot JJB, Hulshof M, van Hagen P, van Berge Henegouwen MI, et al. Neoadjuvant chemoradiotherapy plus surgery versus surgery alone for oesophageal or junctional cancer (CROSS): long-term results of a randomised controlled trial. Lancet Oncol. 2015;16:1090-8.

21. Noordman BJ, Spaander MCW, Valkema R, Wijnhoven BPL, van Berge Henegouwen MI, Shapiro J, et al. Detection of residual disease after neoadjuvant chemoradiotherapy for oesophageal cancer (preSANO): a prospective multicentre, diagnostic cohort study. Lancet Oncol. 2018;19:965-74.

22. Noordman BJ, Wijnhoven BPL, Lagarde SM, Boostra JJ, Coene PPLO, Dekker JWT, et al. Neoadjuvant chemoradiotherapy plus surgery versus active surveillance for oesophageal cancer: a stepped-wedge cluster randomised trial. BMC Cancer. 2018;18:142.

23. Allum WH, Stenning SP, Bancewicz J, Clark PI, Langley RE. Long-term results of a randomized trial of surgery with or without preoperative chemotherapy in esophageal cancer. J Clin Oncol. 2009;27:5062-7.
24. Cunningham D, Allum WH, Stenning SP, Thompson JN, van de Velde CJ, Nicolson M, et al. Perioperative chemotherapy versus surgery alone for resectable gastroesophageal cancer. N Engl J Med. 2006;355:11-20.

25. Ychou M, Boige V, Pignon JP, Conroy T, Bouche O, Lebreton $\mathrm{G}$, et al. Perioperative chemotherapy compared with surgery alone for resectable gastroesophageal adenocarcinoma: an FNCLCC and FFCD multicenter phase III trial. J Clin Oncol. 2011;29:1715-21.

26. Al-Batran SE, Homann N, Pauligk C, Goetze TO, Meiler J, Kasper $\mathrm{S}$, et al. Perioperative chemotherapy with fluorouracil plus leucovorin, oxaliplatin, and docetaxel versus fluorouracil or capecitabine plus cisplatin and epirubicin for locally advanced, resectable gastric or gastro-oesophageal junction adenocarcinoma (FLOT4): a randomised, phase 2/3 trial. Lancet. 2019;393:1948-57.

27. Reynolds JV, Preston SR, O’Neill B, Baesgaard L, Griffin SM, Mariatte C, et al. ICORG 10-14: NEOadjuvant trial in Adenocarcinoma of the oEsophagus and oesophagoGastric junction International Study (Neo-AEGIS). BMC Cancer. 2017;17:401.

28. Hoeppner J, Lordick F, Brunner T, Glatz T, Bronsert P, Röthling $\mathrm{N}$, et al. ESOPEC: prospective randomized controlled multicenter phase III trial comparing perioperative chemotherapy (FLOT protocol) to neoadjuvant chemoradiation (CROSS protocol) in patients with adenocarcinoma of the esophagus (NCT02509286). BMC Cancer. 2016;16:503.

29. Leong T, Smithers BM, Michael M, Gebski V, Boussioutas A, Miller D, et al. TOPGEAR: a randomised phase III trial of perioperative ECF chemotherapy versus preoperative chemoradiation plus perioperative ECF chemotherapy for resectable gastric cancer (an international, intergroup trial of the AGITG/TROG/EORTC/ NCIC CTG). BMC Cancer. 2015; 15:532.

30. Masuda M, Endo S, Natsugoe S, Shimizu H, Doki Y, Hirata Y, et al. Thoracic and cardiovascular surgery in Japan during 2015. Gen Thorac Cardiovasc Surg. 2018;66:581-615.

31. Biere SS, van Berge Henegouwen MI, Maas KW, Maas KW, Bonavina L, Rosman C, et al. Minimally invasive versus open oesophagectomy for patients with oesophageal cancer: a multicentre, open-label, randomised controlled trial. Lancet. 2012;379:1887-922.

32. Straatman J, van der Wielen N, Cuesta MA, Daams F, Roig Garcia J, Bonavina L, et al. Minimally invasive versus open esophageal resection: three-year follow-up of the previously reported randomized controlled trial: the TIME trial. Ann Surg. 2017;266:232-6.

33. Mariette C, Markar SR, Dabakuyo-Yonli TS, Meunier B, Pezet D, Collet D, et al. Hybrid minimally invasive esophagectomy for esophageal cancer. N Engl J Med. 2019;380:152-62.

34. Baba H. National Clinical Database (NCD) in Japan: clinical and social significance. Ann Gastroenterol Surg. 2019. https://doi. org/10.1002/ags3.12282.

35. Takeuchi H, Miyata H, Ozawa S, Udagawa H, Osugi H, Konno $\mathrm{H}$, et al. Comparison of short-term outcomes between open and minimally invasive esophagectomy for esophageal cancer using a nationwide database in Japan. Ann Surg Oncol. 2017;24:1821-7.

36. Yoshida N, Yamamoto H, Baba H, Miyata H, Watanabe M, Toh $\mathrm{Y}$, et al. Can minimally invasive esophagectomy replace open esophagectomy for esophageal cancer? Latest analysis of 24,233 esophagectomies from the Japanese National Clinical Database. Ann Surg. 2019. https://doi.org/10.1097/SLA.000000000000322 2.

37. Kataoka K, Takeuchi H, Mizusawa J, Ando N, Tsubosa Y, Koyanagi $\mathrm{K}$, et al. A randomized phase III trial of thoracoscopic versus open esophagectomy for thoracic esophageal cancer: Japan Clinical Oncology Group Study JCOG1409. Jpn J Clin Oncol. 2006;46:174-7. 
38. Feng MX, Wang H, Zhang Y, Tan LJ, Xu ZL, Qun W. Minimally invasive esophagectomy for esophageal squamous cell carcinoma: a case-control study of thoracoscope versus mediastinoscope assistance. Surg Endosc. 2012;26:1573-8.

39. Fujiwara H, Shiozaki A, Konishi H, Komatsu S, Kubota T, Ichikawa D, et al. Hand-assisted laparoscopic transhiatal esophagectomy with a systematic procedure for en bloc infracarinal lymph node dissection. Dis Esophagus. 2016;29:131-8.

40. Fujiwara H, Shiozaki A, Konishi H, Kosuga T, Komatsu S, Ichikawa D, et al. Perioperative outcomes of single-port mediastinoscope-assisted transhiatal esophagectomy for thoracic esophageal cancer. Dis Esophagus. 2017;30:1-8.

41. Mori K, Yamagata Y, Wada I, Shimiza N, Nomura S, Seto Y. Robotic-assisted totally transhiatal lymphadenectomy in the middle mediastinum for esophageal cancer. J Robot Surg. 2013;7:385-7.

42. Mori K, Yamagata Y, Aikou S, Nishida M, Kiyokawa T, Yagi $\mathrm{K}$, et al. Short-term outcomes of robotic radical esophagectomy for esophageal cancer by a nontransthoracic approach compared with conventional transthoracic surgery. Dis Esophagus. 2016;29:429-34.

43. van Hillegersberg R, Boone J, Draaisma WA, Broeders IA, Giezeman MJ, Borel Rinkes IH. First experience with robot-assisted thoracoscopic esophagolymphadenectomy for esophageal cancer. Surg Endosc Other Interv Tech. 2006;20:1435-9.

44. Kim DJ, Park SY, Lee S, Kim HI, Hyung WJ. Feasibility of a robot-assisted thoracoscopic lymphadenectomy along the recurrent laryngeal nerves in radical esophagectomy for esophageal squamous carcinoma. Surg Endosc. 2014;28:1866-73.

45. Ruurda JP, van der Sluis PC, van der Horst $S$, van Hilllegersberg R. Robot-assisted minimally invasive esophagectomy for esophageal cancer: a systematic review. J Surg Oncol. 2015;112:257-65.

46. van der Sluis PC, van der Horst S, May AM, Schippers C, Brosend LAA, Joore HCA, et al. Robot-assisted minimally invasive thoracolaparoscopic esophagectomy versus open transthoracic esophagectomy for resectable esophageal cancer: a randomized controlled trial. Ann Surg. 2019;269:621-30.

47. Kato K, Muro K, Minashi K, Ohtsu A, Ishikura S, Boku N, et al. Phase II study of chemoradiotherapy with 5-fluorouracil and cisplatin for Stage II-III esophageal squamous cell carcinoma: JCOG trial (JCOG 9906). Int J Radiat Oncol Biol Phys. 2011;81:684-90.

48. Nomura M, Kato K, Ando N, Ohtsu A, Muro K, Igaki H, et al. Comparison between neoadjuvant chemotherapy followed by surgery and definitive chemoradiotherapy for overall survival in patients with clinical stage II/III esophageal squamous cell carcinoma (JCOG1406-A). Jpn J Clin Oncol. 2017;47:480-6.

49. Hayami M, Watanabe M, Ishizuka N, Mine S, Imamura Y, Okamura A, et al. Prognostic impact of postoperative pulmonary complications following salvage esophagectomy after definitive chemoradiotherapy. J Surg Oncol. 2018;117:1251-9.

50. Minsky BD, Pajak TF, Ginsberg RJ, Pisansky TM, Martenson J, Komaki R, et al. INT 0123 (Radiation Therapy Oncology Group 94-05) phase III trial of combined-modality therapy for esophageal cancer: high-dose versus standard-dose radiation therapy. J Clin Oncol. 2002;20:1167-74

51. Kato K, Nakajima TE, Ito Y, Katada C, Ishiyama H, Tokunaga SY, Tanaka M, et al. Phase II study of concurrent chemoradiotherapy at the dose of 50.4 Gy with elective nodal irradiation for Stage II-III esophageal carcinoma. Jpn J Clin Oncol. 2013;43:608-15.

52. Ito Y, Takeuchi H, Ogawa G, Kato K, Onozawa M, Minashi K, et al. A single-arm confirmatory study of definitive chemoradiotherapy (dCRT) including salvage treatment in patients with clinical stage II/III esophageal carcinoma (JCOG0909). J Clin Oncol. 2019;36(15 suppl):4051.

53. Ohtsu A, Boku N, Muro K, Chin K, Muto M, Yoshida S, et al. Definitive chemoradiotherapy for T4 and/or M1 lymph node squamous cell carcinoma of the esophagus. J Clin Oncol. 1999;17:2915-21.

54. Ishida K, Ando N, Yamamoto S, Ide H, Shinoda M. Phase II study of cisplatin and 5-fluorouracil with concurrent radiotherapy in advanced squamous cell carcinoma of the esophagus: a Japan Esophageal Oncology Group (JEOG)/Japan Clinical Oncology Group trial (JCOG9516). Jpn J Clin Oncol. 2004;34:615-9.

55. Shinoda M, Ando N, Kato K, Ishikura S, Kato H, Tsubosa Y, et al. Randomized study of low-dose versus standard-dose chemoradiotherapy for unresectable esophageal squamous cell carcinoma (JCOG0303). Cancer Sci. 2015;106:407-12.

56. Higuchi K, Koizumi W, Tanabe S, Sasaki T, Katada C, Ishiyama $\mathrm{H}$, et al. A phase I trial of definitive chemoradiotherapy with docetaxel, cisplatin, and 5-fluorouracil (DCF-R) for advanced esophageal carcinoma: Kitasato digestive disease \& oncology group trial (KDOG 0501). Radiother Oncol. 2008;87:398-404.

57. Higuchi K, Komori S, Tanabe S, Katada C, Azuma M, Ishiyama $\mathrm{H}$, et al. Definitive chemoradiation therapy with docetaxel, cisplatin, and 5-fluorouracil (DCF-R) in advanced esophageal cancer: a phase 2 trial (KDOG 0501-P2). Int J Radiat Oncol Biol Phys. 2014;89:872-9.

58. Tomasello G, Petrelli F, Ghidini M, Russo A, Passalacquq R, Barni S. FOLFOXIRI plus bevacizumab as conversion therapy for patients with initially unresectable metastatic colorectal cancer: a systematic review and pooled analysis. JAMA Oncol. 2017;3:e170278-e170278170278.

59. Yokota T, Kato K, Hamamoto Y, Tsubosa Y, Ogawa H, Ito Y, et al. Phase II study of chemoselection with docetaxel plus cisplatin and 5-fluorouracil induction chemotherapy and subsequent conversion surgery for locally advanced unresectable oesophageal cancer. $\mathrm{Br}$ J Cancer. 2016;115:1328-34.

60. Terada M, Hara H, Daiko H, Mizusawa J, Kadato T, Hori K, et al. Phase III study of tri-modality combination therapy with induction docetaxel plus cisplatin and 5-fluorouracil versus definitive chemoradiotherapy for locally advanced unresectable squamouscell carcinoma of the thoracic esophagus (JCOG1510: TRIANgLE). Jpn J Clin Oncol. 2019. https://doi.org/10.1093/jjco/hyz11 2.

61. Dong H, Strome SE, Salomao DR, Tamura H, Hirano F, Flies DB, et al. Tumor-associated B7-H1 promotes T-cell apoptosis: a potential mechanism of immune evasion. Nat Med. 2002;8:793-800.

62. Doi T, Piha-Paul SA, Jalal SI, Saraf S, Lunceford J, Koshiji $\mathrm{M}$, et al. Safety and antitumor activity of the anti-programmed death-1 antibody pembrolizumab in patients with advanced esophageal carcinoma. J Clin Oncol. 2018;36:61-7.

63. Kojima T, Muro K, Francois E, Hsu CH, Moriwaki T, Kin SB, et al. Pembrolizumab versus chemotherapy as second-line therapy for advanced esophageal cancer: phase III KEYNOTE-181 study. J Clin Oncol. 2019;37:2-2.

64. Kato K, Shah MA, Enzinger P, Bennouna J, Shen L, Adenis A, et al. KEYNOTE-590: phase III study of first-line chemotherapy with or without pembrolizumab for advanced esophageal cancer. Future Oncol. 2019;15:1057-66.

Publisher's Note Springer Nature remains neutral with regard to jurisdictional claims in published maps and institutional affiliations. 